\title{
THE IMPACT OF SPEECH AND LANGUAGE DISORDERS ON PUPILS', LEARNING AND SOCIALIZATION IN SCHOOLS OF KALOMO DISTRICT-ZAMBIA
}

\author{
Awoniyi Samuel Adebayo, Ph.D \\ Associate Professor and Director Quality Assurance, Solusi University, \\ Zimbabwe \\ Malikana Mabuku \\ Kalomo Secondary School, Private Bag 1, Kaloma, Zambia
}

\begin{abstract}
This study investigated the impact of speech and language disorders on pupils' learning and socialization in schools of Kalomo District, Zambia. The Descriptive research design was employed for the study. The sample consisted of 48 pupils with speech and language disorders purposively selected from 6 schools. The instruments used for data collection were a questionnaire and a test for speech and language disorders. The instruments were both faced and content validated by experts. The questionnaires and test items were taken to experts at the University of Zambia and the Zambia Institute for Special Education (department of speech and language disorders) for validation. The questionnaire and the test were administered to the sampled students. The data collected were coded and analysed using the Statistical Packages for Social Sciences. Descriptive statistics and the regression analysis were employed. The result of the study revealed that the performance of pupils with speech and language disorder in English Language was low, but were average in their socialization. It was also discovered that $77.2 \%$ variance in academic performance was accounted for by the level of speech and language disorders. The positive beta value of 11.885 showed that, the less the severity of speech and language disorder, the better was the academic performance of pupils. The study also revealed that type of disorder and socialization accounted for $79 \%$ variance in academic performance. Type of disorder accounted $77.2 \%$ while socialization accounted $1.8 \%$. The positive beta value of 11.648 for the type of disorder, and 6.099 for socialization indicated that, the less the severity of the disorder and the more pupils with speech and language disorders
\end{abstract}


socialize the better is their academic performance. Type of disorder had greater influence on their academic performance.

Keywords: Speech disorder, Language disorder, Learning, Socialization, Disabilities, Articulation disorder, Communication disorder, Stuttering

\section{Introduction}

Speech-language disorders are the most common of childhood disabilities that affect about 1 in 12 children or $5 \%$ to $8 \%$ of pre-school children (Disability info: speech and language disorders Factsheet (FS11), 2008). A speech and language disorder refers to an impairment of speech or sound production, fluency, voice or language which significantly affects children's educational performance or their social, emotional or vocational development. Children may stutter or experience problems with articulating words. They may have a lisp or voice disorder. Children who have a hearing loss commonly experience difficulties with speech as well.

The inability to articulate speech sounds correctly could be caused by biological factors, such as brain damage, damage to the nerves controlling the muscles used in speech or gross abnormalities of the oral structures like a cleft palate (Hardman, Drew and Egan, 2002). Other possible conditions that might contribute to speech and language disorders are environmental factors such as the quality of parent-child communication, emotional disturbances, and hearing loss. Speech and language disorders are characterized by fluency disorder, articulation disorder, and voice disorder.

In Zambia, the most frequently quoted figure in the speech pathology literature suggested that about $7-10 \%$ of the population is affected (Hardman, Drew and Egan, 2002). Majority of children with speech and language disorders do receive their education in the mainstream, except for fewer severe cases that could be handled in special schools. These children have difficulties in producing sounds properly, maintaining an appropriate flow or rhythm in speech, or using voice effectively. At the same time, they have problems in understanding or expressing the symbols and rules people use to communicate with each other. These may affect their level of socialization as well as academic success.

The Educational reforms document of 1977, focus on learning document of 1992, and educating our future document of 1996, all made emphasis that every child in Zambia has a right to education. This right is not limited by any disability, physical or mental, from which the child may suffer. Therefore, the school system must provide for the needs of those who are disabled and those who are able to benefit from education, including children with speech and language disorders (Ministry of Education, 2008). 
There was little understanding among many Zambians on how lack of fluent speech and language could affect the child's academic performance. The ability to communicate with peers and adults in the educational setting is essential for pupils to succeed in school. According to Hardman, Drew and Egan, (2002), children with communication disorders frequently did not perform as expected at grade level. They may struggle with reading, have difficulties in understanding and expressing language, misunderstand social cues, avoid attending school, poor social interaction, and under achieves in tests.

Most speech and language disorders exhibited by school children are developmental, that is, roots of the problem exist from birth and manifestations of the problem emerge as the child develops and it becomes obvious that is slower or atypical compared to peers. In a minority of cases, speech and language disorders are acquired when a child suffers from an illness or accident that affects brain function. This type of speech disorder is known as aphasia (American Speech-Language-Hearing Association (ASHA), 2000).

Pre-school children identified as language disordered often have long term problems with language and academic skills. The school aged language disordered children may continue to have difficulty in expressing their ideas. They may begin to compensate by producing only short, simple sentences on which they are not likely to make a grammatical error or they may avoid talking, except when necessary. They may also have difficulty in comprehending complex sentences and figurative language such as idioms and metaphors. Poor language skills put these children at risk for reading problems. Therefore, it is not surprising that even children with relatively mild language disorders may have academic problems (Plante and Beeson, 2004).

On socialization, Mansson (2000) asserted that socialization was a developmental process in which an individual came in contact with people and things that allowed them to be socially acceptable. This process begins at birth and is constant throughout a person's entire life-span. There are many things that could factor a person's perception of the world as they see it and how they behave in it. These influences are known as socializing agents, which are determined by the surroundings and experiences the individual has been exposed to. Socialization agents may bring both positive and negative impacts to an individual.

According to Smith and Tyler, (2009) the early stages of an individual's life span dictate the vulnerability and dependant on others to guide him or her. This responsibility comes to the parents to teach their children with speech and language disorders, the right from wrong according to their socially acceptable attitudes. A child also learns things from other 
members of the household such as siblings or other relatives. However, the predominant influence is that of the parents. Parents play a big role because they are primarily in control of the individual during childhood and adolescent years. The involvement of parents can be a good ground for model behaviour. However, it could also have a negative impact on the child. Situations such as violent environment could greatly impact how children think, act and emotionally feel.

Thomas (2009) postulated that children with speech and language disorders needed additional opportunities to both talk and listen; yet due to their disability may be presented to fewer chances. Children with speech and language disorders who could not get their message across may simply stop trying. Morales (2009) argued that speech could seriously limit the manner in which an individual interacted with others in school, social, and even home environments. Inability to correctly form speech sounds might create stress, embarrassment, and frustration in both the speaker and the listener. Over-time, this could create aggressive response on the part of the listener for being misunderstood or out of embarrassment. Alternatively, it could generate an avoidance of social situations that created these stressful situations.

Smith and Tyler (2009) supported the above statement when they stated that language disorders created similar difficulties in communicating with others, but may also include difficulties in understanding what others were to say (receptive language). Because of the pervasive nature of language disorders, communicating, reading, writing, and academic success could all be compromised in these pupils. Similar to individuals with speech disorders, individual with language disorders also encountered a long term difficulties associated with school, social, and home environment.

Blood, Boyle, Blood and Nalesnik (2010) also stated that children with speech and language disorders could easily be bullied and was more common in childhood. Bullying involves the consistent and intentional harassment of individual, and may be physical or verbal in nature. This trend has a great effect on the socialization of children with speech and language disorders. Blood, Blood, Tramontana, Sylvia, Boyle and Motzko (2011) stipulated that the social implications of speech and language disorders were so powerful that they had the potential to influence self-esteem, depression levels and academic success. Blood, Blood, Tellis and Gabel (2003) equally indicated that the stigmatization associated with speech disorders influenced self-esteem, as children with speech disorders often experienced depression, social isolation, and poorer performance on academics and standardized tests. Social acceptance, confidence, and overall life satisfaction could be at stake. Without the ability to hold fluent and successful conversations, many huge milestones such as maintaining friendships could be unsuccessful. 
Individuals with speech impediments could become a target for exclusion and bullying.

The above statement is supported by Ross and Weinberg (2006) when they stated that inability or hesitancy to communicate hindered connections to others. Often individuals who struggled with language will have a tougher time making and maintaining friendships. In addition to challenges of bonding with peers, individuals who have speech disorders are more likely to have lower life satisfaction (Blood etal, 2011). Rose (2005) noted that children with speech and language disorders have a harder time in the classroom than children without speech and language disorders. Reading, comprehension, spelling, writing, and mathematics prove to be a problem to them. It is against this background that the study investigated the impact of speech and language disorders on pupils' learning and socialization in schools of Kalomo District, Zambia.

\section{ResearchQuestions}

1. What is the general academic performance of pupils with speech and language disorders in English language?

2. To what degree do pupils with speech and language disorders socialized with other pupils?

3. To what extent is the academic performance of pupils with speech and language disorders affected by the level of speech and language disorder?

4. To what extent is the academic performance of pupils with speech and language disorders affected by their level of disorder and socialization?

\section{Research Hypothesis}

1. The academic performance of pupils with speech and language disorder is not affected by levels of disorder and socialization.

\section{Research methodology}

The study investigated the impact of speech and language disorders on pupils' learning and socialization in schools. The quantitative and qualitative descriptive research designs were employed. The population for the study was drawn from 6 schools of Kalomo district with a population of 48 learners with speech and language disorders. All the 48 learners were selected purposively and used for the study. Of the 48 pupils with speech and language disorders used for the study, 29 (60.4\%) were male while 19 (39.6\%) were female. Eighteen (37.5\%) were in grades 5-8 and 30 (62.5\%) in grades $9-12$. On the types of disorders, 9 (18.8\%) had Language problems, 
9 (18.8\%) Articulation, 15 (31.2\%) Fluency and the remaining 15 (31.2\%) had voice problems.

Questionnaire and test items were the sole instruments for data collection. The August 2013 school end of term English results was used as a measure for academic performance of the learners. A test was also administered by the researcher to find out the levels of pupils' speech and language disorders. To ascertain the validity and reliability of the questionnaire and test items as an instrument for data collection, one expert in the department of speech and language disorders at the Zambia Institute of Special Education (ZAMISE) and the other two experts from the University of Zambia were consulted. These three experts moderated the research questions and test items before the researchers administered them to the learners. The data were coded and analysed using the statistical packages for social sciences (SPSS version 16). The descriptive statistics and the Regression analysis were employed.

\section{Results}

Research QuestionOne: What is the general academic performance of pupils with speech and language disorders in English language?

Table 1 presents the academic performance of pupils with speech and language disorders in the August 2013 end of term examination in English language.

Table 4.1: Academic Performance

\begin{tabular}{|c|c|c|c|}
\hline Grade Range & Description & Frequency & Percentage \\
\hline $0-39$ & Fail & 15 & 31.2 \\
$40-59$ & Pass & 24 & 50.0 \\
\hline $60-74$ & Merit & 9 & 18.8 \\
$75----$ Above & Distinction & & \\
\hline
\end{tabular}

It is evident from the table that $9(18.8 \%)$ of pupils had merits in the school end of term examination, 24 (50\%) obtained pass grades, while 15 (31.2\%) failed. This is a clear indication that the majority of the pupils with speech and language disorders performed at a lower level. It is noteworthy that none of the pupils with speech and language disorders had distinction. The above finding is supported by Hardman, Drew and Egan (2000) when they stipulated that children with speech and language disorders did not frequently perform as expected at grade level because of their continuous struggling with reading and under achievements in tests.

Research Question2: To what degree do pupils with speech and language disorders socialize with other pupils?

From table 2 below, pupils with speech and language disorders agreed that they avoided social situations that created stress, avoided speaking in order to reduce frustration and embarrassment with colleagues, 
experienced bullying from other pupils due to their speech and language disorders and also failed to differentiate jokes from sarcasm with mean scores of 1.8723, 2.0208, 2.3958 and 1.7708, respectively. The low standard deviations of 0.82402 and 0.86884 for avoiding social situations that created stress and experiencing bullying from other pupils respectively showed that the pupils were homogeneous in their responses.

Table 2: Descriptive Statistics

\begin{tabular}{|c|c|c|}
\hline Items & Mean & $\begin{array}{l}\text { Std. } \\
\text { Deviation }\end{array}$ \\
\hline I have a successful social interaction across school community & 3.4167 & 1.39655 \\
\hline I am always involved in a social play when at school & 3.3958 & 1.19822 \\
\hline I do not avoid social situations that create stress & 1.8723 & .82402 \\
\hline I am easily accepted by other pupils during social learning & 3.4375 & 1.23609 \\
\hline $\begin{array}{l}\text { I do not avoid speaking in order to reduce frustration and } \\
\text { embarrassment when with colleagues }\end{array}$ & 2.0208 & 1.06170 \\
\hline $\begin{array}{l}\text { I have not experienced bullying from other pupils due to my speech and } \\
\text { language disorders }\end{array}$ & 2.3958 & .86884 \\
\hline I have no problem in making friends & 4.2917 & .94437 \\
\hline $\begin{array}{l}\text { I fail to differentiate jokes from sarcasm because of speech and } \\
\text { language disorders }\end{array}$ & 1.7708 & 1.09621 \\
\hline I am able to express thoughts and feelings of other pupils & 3.8750 & 1.16006 \\
\hline I have no difficulties in getting words started & 3.0208 & 1.36038 \\
\hline $\begin{array}{l}\text { I have equal social status with pupils who are developing normally, in } \\
\text { school }\end{array}$ & 4.2083 & .94437 \\
\hline My friends always assist me pronounce difficulty words when playing & 2.9792 & 1.40651 \\
\hline $\begin{array}{l}\text { I do not experience social isolation because of speech and language } \\
\text { disorders }\end{array}$ & 2.5625 & .98729 \\
\hline $\begin{array}{l}\text { I do not produce short simple sentences in order to avoid grammatical } \\
\text { errors }\end{array}$ & 1.5833 & .61310 \\
\hline I have no problem in expressing ideas & 4.0625 & .90873 \\
\hline I can easily understand the spoken language of others & 3.0208 & 1.36038 \\
\hline I have a lot of chances to talk when playing & 2.4583 & 1.18426 \\
\hline I can easily hear when my friend call me & 1.7708 & .83129 \\
\hline I have no problem in using language in different social situations & 4.0208 & .95627 \\
\hline $\begin{array}{l}\text { I am encouraged by my friends to talk about activities that are outside } \\
\text { the school }\end{array}$ & 2.3125 & 1.18781 \\
\hline Socialization Average & 2.9340 & .36729 \\
\hline
\end{tabular}


The pupils with speech and language disorders also agreed that they produced short simple sentences in order to avoid grammatical errors, had fewer chances to talk when playing, could easily hear calls from friends and that they were usually encouraged by friends to talk with the means of $1.5833,2.4583,1.7708$ and 2.3125 , respectively. They were homogeneous in their responses on the use of short simple sentences and easily heard when called by friends. The pupils were found to either disagree or indifferent on other socialization items. The overall mean of 2.9340 showed that pupils with speech and language disorders were moderate in their socialization while the standard deviation of .36729 indicated that they were homogeneous in their responses.

Research Question3: To what extent is the academic performance of pupils with speech and language disorders affected by the level of speech and language disorder?

Tables 3a and 3b below, show the model summary and the coefficients for the Regression analysis on the effect of level of speech and language disorders on pupils' academic performance.

The model summary showed that $77.2 \%$ variance in academic performance is accounted for by the level of speech and language disorders. The $\mathrm{F}$ value of 159.926 was found to be significant, an indication that the results of the regression analysis was true and not by chance. The high coefficient of 0.881 showed that there was a high positive relationship between the level of speech and language disorders and pupils' academic performance.

Table 4.3 (a) model summary

\begin{tabular}{|c|c|c|c|c|c|c|c|c|c|}
\hline \multirow[b]{2}{*}{ Model } & \multirow[b]{2}{*}{$\mathrm{R}$} & \multirow{2}{*}{$\begin{array}{c}\mathrm{R} \\
\text { Square }\end{array}$} & \multirow{2}{*}{$\begin{array}{l}\text { Adjusted } \\
\text { R Square }\end{array}$} & \multirow{2}{*}{$\begin{array}{l}\text { Std. Error } \\
\text { of the } \\
\text { Estimate }\end{array}$} & \multicolumn{5}{|c|}{ Change Statistics } \\
\hline & & & & & $\begin{array}{l}\text { R Square } \\
\text { Change }\end{array}$ & $\begin{array}{c}\mathrm{F} \\
\text { Change }\end{array}$ & df1 & df2 & $\begin{array}{l}\text { Sig. F } \\
\text { Change }\end{array}$ \\
\hline 1 & $.881^{\mathrm{a}}$ & .777 & .772 & 7.07765 & .777 & 159.926 & 1 & 46 & .000 \\
\hline
\end{tabular}

a. Predictors: (constant). Types of Disorder. $F=159.926$, Sig $=0.000$

Table 3b shows the coefficients for the regression analysis on the effect of level of speech and language disorders on pupils' academic performance. The positive beta value of 11.885 showed that the less the severity of speech and language disorder, the better is the performance of pupils. In support of the above statement, Plante and Beeson (2004) stated that pupils with speech and language disorders have long term problems with language and academic skills. These children may continue to have difficulty in expressing their ideas. They may also have difficulty in comprehending complex sentences and figurative language such as idioms and metaphors. 
Therefore, it is not surprising that even children with relatively mild language disorders may have academic problems, though at a minimum level.

Table 3b: Coefficients ${ }^{\mathrm{a}}$

\begin{tabular}{|c|c|c|c|c|c|c|}
\hline & \multirow{2}{*}{ Model } & \multicolumn{2}{|c|}{$\begin{array}{l}\text { Unstandardized } \\
\text { Coefficients }\end{array}$} & $\begin{array}{l}\text { Standardized } \\
\text { Coefficients }\end{array}$ & \multirow[t]{2}{*}{$\mathrm{t}$} & \multirow[t]{2}{*}{ Sig. } \\
\hline & & B & Std. Error & Beta & & \\
\hline \multirow{2}{*}{1} & (Constant) & 21.982 & 1.933 & & 11.374 & .000 \\
\hline & Types of Disorder & 11.855 & .937 & .881 & 12.646 & .000 \\
\hline
\end{tabular}

a. Dependent Variable: Academic Performance

Research Question4: To what extent is the academic performance for pupils with speech and language disorders affected by their level of disorder and socialization?

Tables 4a and 4b show the extent to which the academic performance of pupils with speech and language disorders were affected by their levels of disorder and socialization

From the Model Summary, type of disorder and socialization accounted for $79 \%$ variance in academic performance. Type of disorder accounted $77.2 \%$ while socialization accounted $1.8 \%$. The $\mathrm{F}$ values were then found to be significant, an indication that the results of the Regression analysis was true. Further, the beta value of 11.648 for the type of disorder, and 6.099 for socialization were found to be positive, an indication that, the less the severity of the disorder and the more pupils with speech and language disorders socialize the better their academic performance. However, the type of disorder was the major factor that affected pupils' academic performance.

Table 4a: Model Summary

\begin{tabular}{|c|c|c|c|c|c|c|c|}
\hline \multirow{2}{*}{$\begin{array}{c}\mathrm{R} \\
\text { Square }\end{array}$} & \multirow{2}{*}{$\begin{array}{c}\text { Adjusted } \\
\text { R Square }\end{array}$} & $\begin{array}{c}\text { Std. Error } \\
\text { of the } \\
\text { Estimate }\end{array}$ & $\begin{array}{c}\text { R Square } \\
\text { Change }\end{array}$ & $\begin{array}{c}\mathrm{F} \\
\text { Change }\end{array}$ & df1 & df2 & $\begin{array}{c}\text { Sig. F } \\
\text { Change }\end{array}$ \\
\hline .777 & .772 & 7.12635 & .777 & 157.058 & 1 & 45 & .000 \\
.800 & .790 & 6.83656 & .022 & 4.896 & 1 & 44 & .032 \\
\hline
\end{tabular}


Table 4b: Coefficients ${ }^{\mathrm{a}}$

\begin{tabular}{|l|c|c|c|c|c|}
\hline \multirow{2}{*}{ Model } & \multicolumn{2}{|c|}{$\begin{array}{c}\text { Unstandardized } \\
\text { Coefficients }\end{array}$} & $\begin{array}{c}\text { Standardized } \\
\text { Coefficients }\end{array}$ & & \\
\cline { 2 - 4 } & $\mathrm{B}$ & Std. Error & Beta & $\mathrm{T}$ & Sig. \\
\hline (Constant) & 4.358 & 8.156 & & .534 & .596 \\
Types of Disorder & 11.648 & .910 & .868 & 12.799 & .000 \\
Socialization & 6.099 & 2.756 & .150 & 2.213 & .032 \\
\hline
\end{tabular}

a. Dependent Variable: Academic Performance

This is in agreement with the assertion of Rose (2005) who noted that children with speech and language disorders have a harder time in the classroom than children without speech and language disorders. In the same vein, Smith and Tyler (2009)n stipulated that the pervasive nature of speech and language disorders in pupils could cause the following problems: communication, reading, writing and academic failure, especially among those with severe or profound disorders.

\section{Findings}

Following are the findings of the study:

1. The general performance of pupils with speech and language disorders in English language was low

2. The overall mean of 2.9340 showed that pupils with speech and language disorders were moderate in their socialization, while the standard deviation of .36729 indicated that they were homogeneous in their responses.

3. Speech and language disorder accounted for $77.2 \%$ variance in academic performance of pupils with speech and language disorders. The positive beta value of 0.881 showed that, the less the severity of speech and language disorder, the better the performance of pupils.

4. Type of disorder and socialization accounted for $79 \%$ variance in academic performance. Type of disorder accounted $77.2 \%$ while socialization accounted $1.8 \%$. The positive beta value of 11.648 for the type of disorder, and 6.099 for socialization indicated that, the less the severity of the disorder and the more pupils with speech and language disorders socialize the better their academic performance.

\section{Conclusion}

The study clearly revealed that the performance of pupils with speech and language disorder was low and that their academic performance was affected by the type of disorder and level of socialization however type of 
disorder had greater influence on their academic performance. The less the severity of the disorder and the more pupils with speech and language disorders socialize the better their academic performance. It was therefore recommended that teachers make early identification of pupils with speech and language disorders upon enrolling in schools for early educational interventions and that District Education Boards organise sensitization programs on the teaching and socialization of pupils with speech and language disorders.

\section{References:}

AmericanSpeech -Language-HearingAssociation (ASHA)(2000) Guidelines for the roles and responsibilities of the school-based speech language pathologist. Retrieved 19.09.13 from http://www.asha.org/docs/htm/gl 200000053

Blood, G., Blood, I., Tramonatana, I., Sylvia, A., Boyle, M. and Motzko, G.(2011: Self-reported experience of bullying of students who stutter: Relations with life satisfaction, life orientation, and self- esteem. Perceptual motor skills,113 (2) 353-364.

Blood, G., Boyle, M., Blood, I., and Nalesnik, G (2010).Bullying in children who stutter: Speech/ language pathologist's' perception and intervention strategies.Journal of Fluency disorders, 35 (2),92-109

Blood, G., Blood, I., Tellis, G., and Gabel, R. (2003).A preliminary study of self-esteem, stigma, and disclosure in adolescents who stutter. Journal of FluencyDisorders, 28 (2), 143-159

Disability info: Speech and language disorders Factsheet (FS 11, 2008).National Dissemination center for children with Disabilities. Retrieved 19.09.13 from http://www nichcy.org/pubs/ factsh /fs 11tt/htm.

Hardman, M.L., Drew, C.L. and Egan, M.W. (2002)Human Exceptionality: Society,School, and family ( $7^{\text {th }}$ ed).Boston: Allyn and Bacon.

Mansson, H. (2000), Childhood stuttering: incidence and development. Journal of fluencydisorders,25, 47-57.

Morales, S. (2009).The Mechanics of speech and language;Retrieved 20.09.13 from http: //www./child speech.net.

Murray, N .and Hughes, G (2008).Writing up your university assignments andresearch projects: A practical Hand book. London: Open University Press.

Nelson, N.W.(2002).Language intervention in school settings, in D .K. Bernstein and E. Tiegerman-Farber (eds). Language and communication disorders in children ( $5^{\text {th }}$ ed) Needham Heights, M. A : Allyn and Bacon. New Deal for communities (2002).The National Evaluation Research Report 31: Parental involvement in Education. Sheffield: Hallam University Press. 
Owens, R. E. Metz, D. E and Haas, A. (2000)Introduction to communicationdisorders.NeedhamHeights: Allyn and Bacon.

Plante, E. and Beeson, P.M. (2008)Communication Disorders A ClinicalIntroduction ( ${ }^{\text {nd }}$ ed). Needham, M.A: Allyn and Bacon.

Rose, J (2005) Independent Review of the teaching of Early Reading: Interim Report.

Ross, G. and Weinberg, S. (2006).Is there a Relationship between language delays and behavior and socialization problems in toddlers?: Journal of early childhood and infant Psychology, (2) 101-116.

Satasha, L. G. and Scott, C.M. (2011).The History of speech and language impairments, in Anthony, F.R Obiakor, F.E and Bakken, J.P. (ed). History of speechEducation Emerald Group Publishing Company.

Smith, D. D. and Tyler, C.N. (2009),Introduction to speech Education: Making a difference $\left(7^{\text {th }} e d\right)$. Englewood cliffs, NJ: Prentice Hall.

Thomas, C.W. (2009).Children and speech or Language impairmentsNew Castle: New CastleUniversity.

Van, R and Erikson (1996) The History of speech and language impairments, in Anthony, F. R., Obiakor, F.E and Bakken, J. P (ed) History of speech Education. Emerald Group. 